Supporting Information

\title{
Functionalized Core-Shell Polystyrene Sphere-Supported Alkaline Imidazolium Ionic Liquid: An Efficient and Recyclable Catalyst for Knoevenagel Condensation
}

Wang Yang ${ }^{\mathrm{a}}$, Hansheng Li*a, Qin Wu*a, Yujing Ren ${ }^{\mathrm{a}}$, Daxin Shi ${ }^{\mathrm{a}}$, Yun Zhao ${ }^{\mathrm{a}}$, Qingze $\mathrm{Jiao}^{\mathrm{a}, \mathrm{b}}$

a. Beijing Key Laboratory for Chemical Power Source and Green Catalysis, School of Chemistry and Chemical Engineering, Beijing Institute of Technology, 100081, Beijing, China

b. School of Chemical Engineering and Materials Science, Beijing Institute of Technology, 519085, Zhuhai, China

*Corresponding author: Tel. / fax: +86-10-68918979; hanshengli@bit.edu.cn, wuqin_bit@126.com

Number of pages: 4

Number of figures: 5

Number of tables: 0 


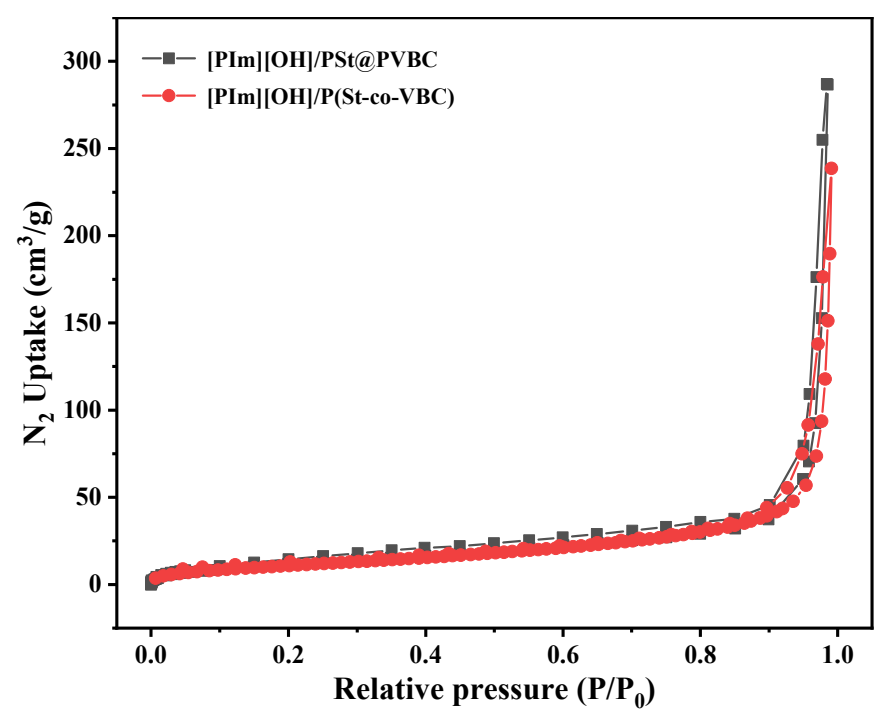

Figure S1. The $\mathrm{N}_{2}$ adsorption-desorption isotherms of [PIm][OH]/PSt@PVBC and $[\mathrm{PIm}][\mathrm{Cl}] / \mathrm{P}(\mathrm{St}-\mathrm{co}-\mathrm{VBC})$.
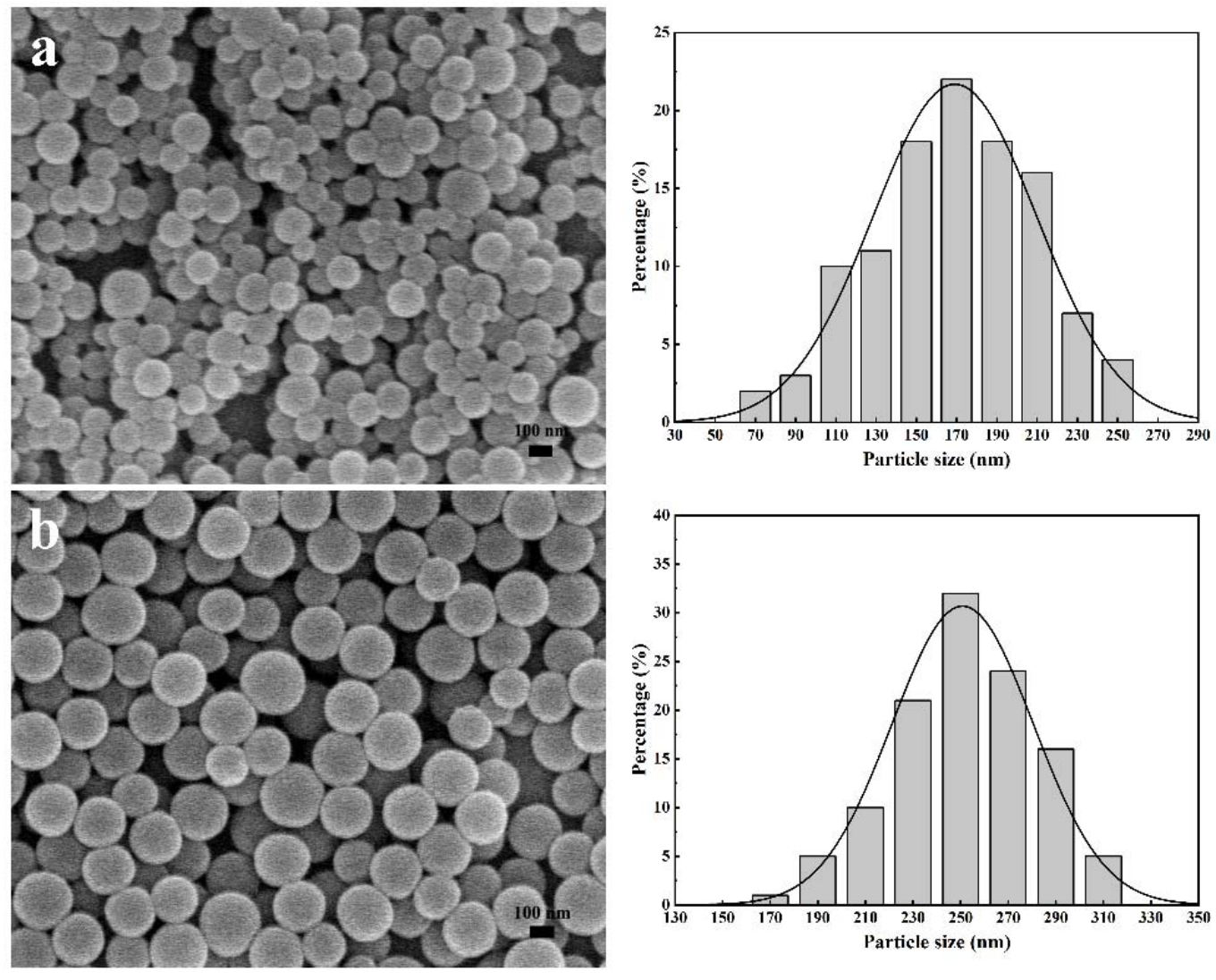

Figure S2. SEM images and particle size distributions of (a) [PIm] $[\mathrm{OH}] / \mathrm{PSt} @ \mathrm{PVBC}$ and (b) $[\mathrm{PIm}][\mathrm{OH}] / \mathrm{P}(\mathrm{St}-\mathrm{co}-\mathrm{VBC})$. 

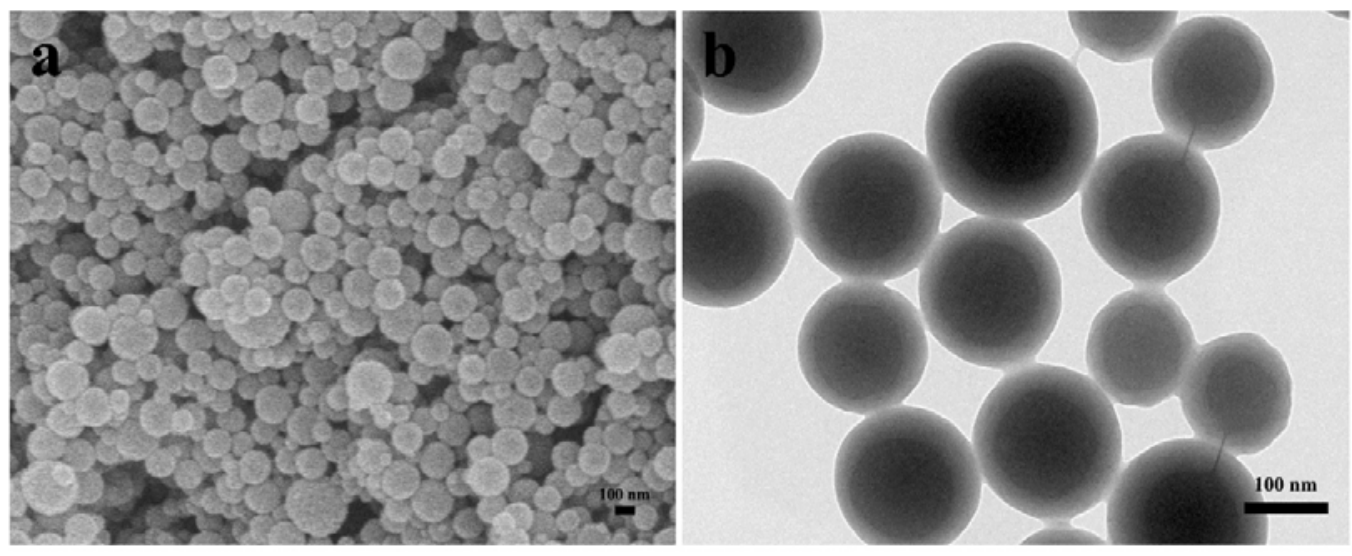

Figure S3. (a) SEM and (b) TEM images of [PIm][OH]/PSt@PVBC after 10 cycles in methanol.

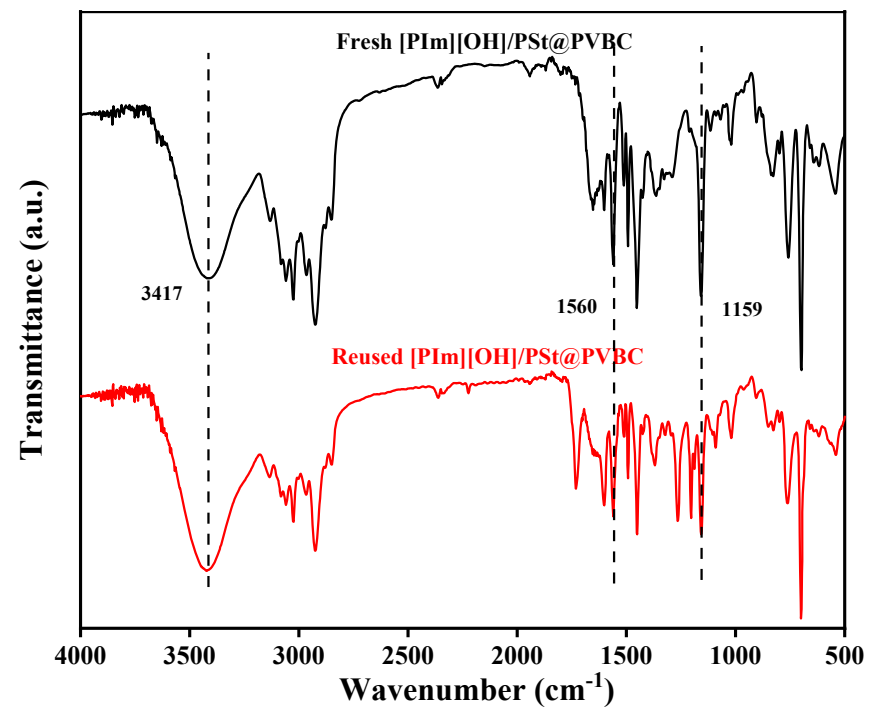

Figure S4. FTIR spectra of [PIm][OH]/PSt@PVBC before and after 10 cycles in methanol. 


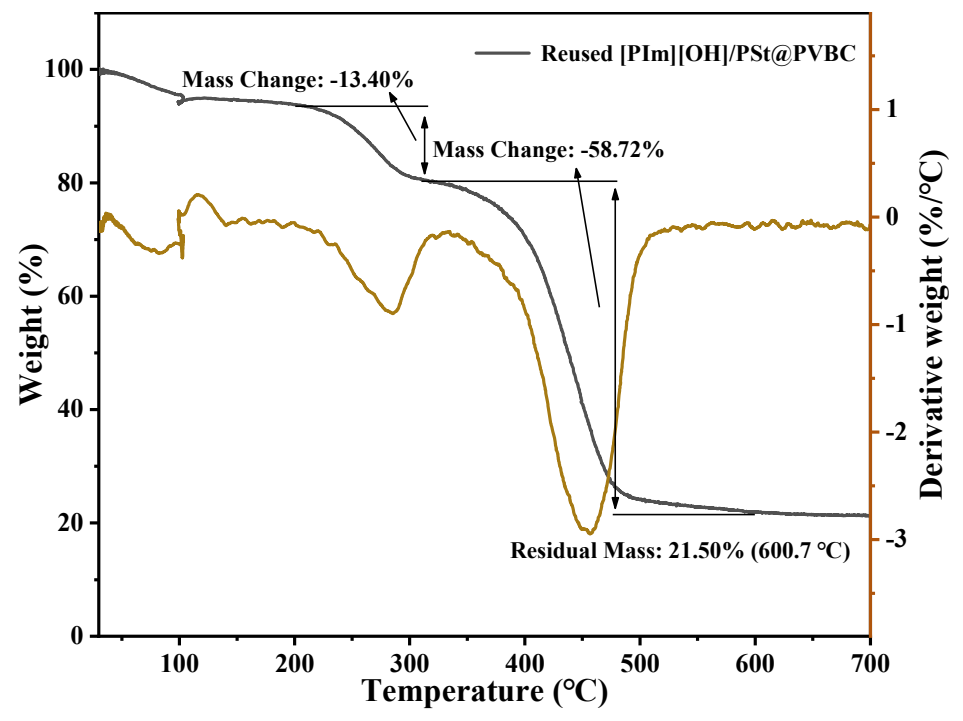

Figure S5. TG and DTG curves of $[\mathrm{PIm}][\mathrm{OH}] / \mathrm{PSt} @ \mathrm{PVBC}$ after 10 cycles in methanol. 